\section{A new apparatus for the study of avoidance conditioning in fishes}

\author{
VICENTE SIMÓN \\ University of Valencia, Valencia, Spain
}

and

\section{DIETRICH E. W. TRINCKER \\ University of Bochum, Bochum 4630, West Germany}

An apparatus for the study of avoidance conditioning in fishes is described. The chamber is cylindrical in shape, with shocking electrodes placed above and below the animals, and response is defined as swimming a predetermined distance in either direction along a circumferential path. This apparatus has several advantages over the conventional shuttlebox: (1) There is little constraint on the direction of swimming; (2) the magnitude of response (swimming distance) required for avoidance can easily be varied over a wide range; and (3) variation in the effectiveness of shock with the position of the animal relative to the position of the electrodes is minimized. Some sample data obtained in a free-operant experiment with goldfish are presented.

Avoidance conditioning in fishes has heretofore been studied almost entirely in the shuttlebox (Homer, Longo, \& Bitterman, 1961) and in experiments of the two-way variety (Olton, 1973). In this paper, a new apparatus, reminiscent of one used earlier for rats by Hunter (1935), is described. Its form is cylindrical, and response consists of swimming a certain distance along the circumferential path. The experiments permitted by this apparatus are, strictly speaking, neither of the one-way nor of the two-way type. As in one-way experiments, the animals can, and usually do, avoid shock by swimming always in the same direction; as in two-way experiments, no region of the apparatus is always safe. An important feature of the apparatus is that the magnitude of the response required for avoidance (defined in terms of the distance to be swum) can easily be varied over a wide range. Another important feature of the apparatus has to do with the location of the electrodes. As expected from body shape and actual measurements of voltage drop (Severin, 1969), there is marked variation in the effectiveness of shock for goldfish as a function of orientation with respect to the electrodes; the effectiveness is greatest for front-back and least for right-left orientations (Woodard \& Bitterman,

The authors are indebted to Professor M. E. Bitterman for advice and encouragement. Address reprint requests to Vicente Simon, Departamento de Psicologia Fisiologica, Facultad de Filosofia y Ciencias de la Educación, Universidad de Valencia, Valencia, Spain.
1971). Given the tendency of the animals to maintain a bodily orientation parallel to the substrate, variation in effectiveness with position in the apparatus is minimal with over-and-under electrodes.

\section{METHOD}

\section{Apparatus}

The apparatus is diagrammed in Figure 1. It consists of a Perspex cylinder, $20 \mathrm{~cm}$ in diameter and $16.5 \mathrm{~cm}$ high. The floor of the test apparatus is white, except for a transparent strip $(1.5 \mathrm{~cm}$ wide) beneath which are two rows of photocells, described below.

Two circular gratings of stainless steel wire netting (the same diameter as the cylinder) serve as electrodes, one resting on the floor and the other $10 \mathrm{~cm}$ above it. A section coinciding with the transparent floor strip is cut out of the lower electrode. The electrodes are attached to a central support, through which the current supply for both electrodes is delivered.

The fish can be inserted in the apparatus through a small trapdoor in the upper electrode. The fish is then free to swim around between the two electrodes.

The movements of the animal are monitored by two optical gates aligned to cover the diameter of the cylinder. The optical

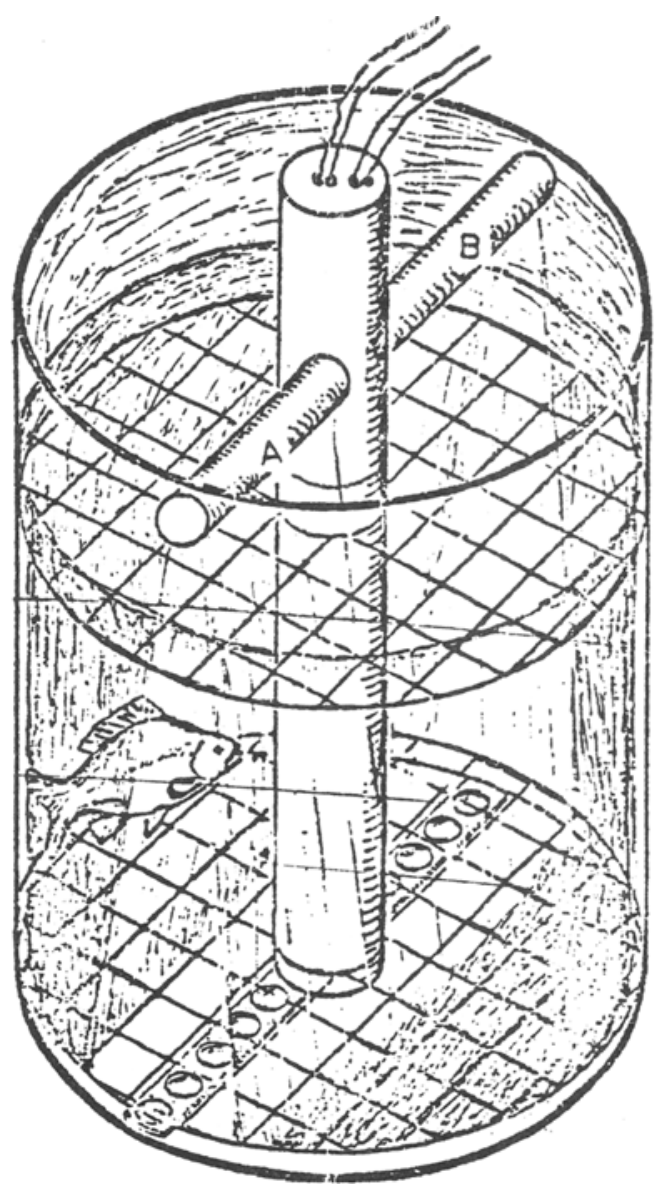

Figure 1. Diagram of the apparatus without the external housing and the trapdoor. 
gates consist of two small strip lamps situated directly above the upper electrode and two rows, each of six photoresistors, below the transparent floor strip. The cylinder is filled with water that just covers the upper electrode.

This entire apparatus is screened by a second black cylindrical housing in the upper opening of which are two small stimulus lamps, one green and one red. These are used for research on discriminated avoidance and will not be discussed in this paper.

The experiments were controlled on-line by means of an IBM 1130 computer. The computer program allowed for the control of four experimental chambers. Two fish chambers were used in the research described here. All experimental data were stored on disk and were output on a plotter.

\section{Procedure}

Nine goldfish (Carassius auratus), $6-7 \mathrm{~cm}$ long, were acquired from a local dealer 2 weeks before the experiments began and were housed in individual aerated home tanks. Room lights were turned off $12 \mathrm{~h}$ each day (from 6:00 p.m. to 6:00 a.m.). The fish were fed once a day at $7: 30 \mathrm{a} . \mathrm{m}$.

The experiments began at 8:00 a.m. Each fish was taken from the home tank to the experimental room and hand placed into the cylinder through the trapdoor. After $5 \mathrm{~min}$, the lamps of the optical gates lit and the sessions began. When a session was completed, the lights went off for about $7 \mathrm{~min}$, and then the next session began.

\section{Experimental Use of Fish Chamber}

Four animals were assigned to the experimental group and received a total of 30 sessions (6 per day). Sessions were 20 min each and consisted of a Sidman avoidance schedule in which both the shock-shock interval and the response-shock interval were $20 \mathrm{sec}$. Response was defined as consecutive crossing of the two optical gates, with no time limitation between crossings. If $20 \mathrm{sec}$ elapsed without a response, the fish received a shock, $19 \mathrm{~mA} / \mathrm{cm}^{2}$ in intensity and $200 \mathrm{msec}$ in duration. A response delayed the next shock $20 \mathrm{sec}$.

A modified yoked control group was introduced in order to control for the possibility that the responses of the experimental group might be due to unspecific effects of shocks (sensitization). (Although the yoking procedure did not meet all criticisms set forth by Church, 1964, the method seemed appropriate for apparatus evaluation.) Two essential modifications were made: All control animals in a given session received shocks equal to the mean number of shocks received by the experimental animals in that session. The timing of shocks was random and determined by a computer program, the shortest interval between consecutive shocks being 2 sec. The same time pattern of random shocks was used for all control animals.

The five control animals received a total of 35 sessions ( 6 each day and then a five-trial shift). In the first 30 sessions, the fish received random shocks as described above. During Sessions 31-35, animals in this group were shifted to the experimental condition, acquiring control over the situation.

\section{RESULTS}

Figure 2 shows that the responses of the experimental group increased across sessions; the number of shocks decreased markedly. The number of shocks was not necessarily related directly to the number of responses; the location of responses in the free shock interval was also decisive. Theoretically, it was possible to avoid all shocks in one session with only 60 responses, optimally placed.
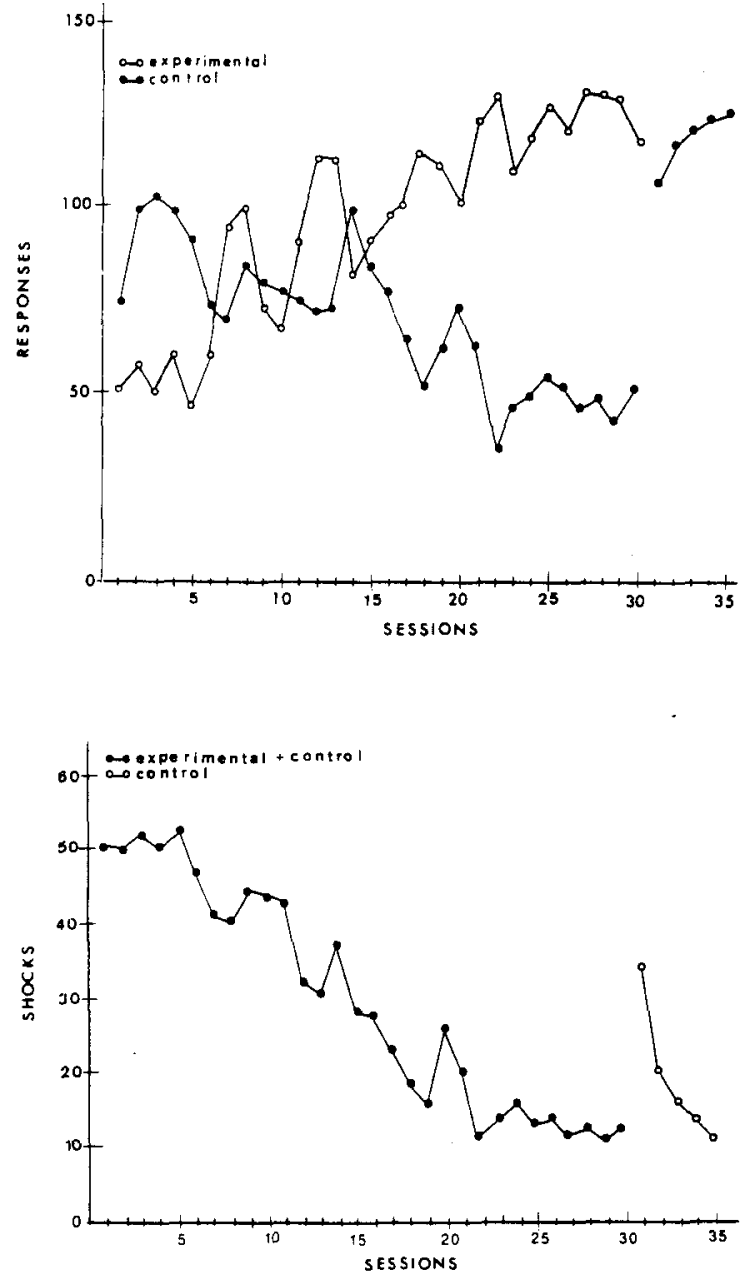

Figure 2. Above: Responses of the control and experimental groups. Below: Shocks were the same for experimental and control groups in the $\mathbf{3 0}$ first sessions. In the last five sessions, only the control group received shocks (see text).

In the control group, on the contrary, responses decreased across sessions $(F=11.07, p=.01)$. Over the last 15 sessions, there was a marked difference in the number of responses of both groups.

In the last five sessions, the control group was shifted to the avoidance situation and the number of responses increased abruptly, reaching the level of the experimental group.

\section{DISCUSSION}

The purpose of the experiment was to establish the feasibility of conditioning fish with the cylindrical chamber and to assess the characteristics of the apparatus. The overall results indicate that conditioning does take place and that it cannot feasibly be explained in terms of sensitization. 


\section{REFERENCES}

Church, R. M. Systematic effect of random error in the yoked control design. Psychological Bulletin, 1964, 62, 122-131.

Horner, J. L., Longo, N., \& Bitterman, M. E. A shuttlebox for the fish and a control circuit of general applicability. American Journal of Psychology, 1961, 74, 114-120.

Hunter, W. S. Conditioning and extinction in the rat. British Journal of Psychology, 1935, 26, 135-148.

OLton, D. S. Shock motivated avoidance and the analysis of behavior. Psychological Bulletin, 1973, 79, 243-251.
Severin, F. T. The placement of shocking electrodes for escape and avoidance learning in fish. Psychonomic Science, 1969, 16, 244-245.

Woodward, W. T., \& Bitterman, M. E. Punishment in the goldfish as a function of electrode orientation. Behavior Research Methods \& Instrumentation, 1971, 82, 72-73.

(Received for publication August 12, 1980; revision accepted December 10, 1980.) 